\title{
ANÁLISE DE ENCURTAMENTO DOS MÚSCULOS ISQUIOTIBIAIS EM ADULTOS JOVENS DE 18 A 25 ANOS
}

José Henrique Piedade Cardoso ${ }^{1}$, Silas de Oliveira Damasceno ${ }^{1,2}$, Daniel Tavares Camara ${ }^{2}$, Fernando Henrique de Souza Miranda ${ }^{2}$, Liamara Cavalcante de Assis ${ }^{2}$, Elaine Aparecida Lozano da Silva $^{1,3}$, Lucas Oliveira Klebis ${ }^{1,3}$ e Ana Caroline Rippi Moreno ${ }^{1}$.

'Universidade Estadual Paulista - UNESP, Especialização em Geriatria e Gerontologia, ${ }^{1,2}$ Especialização em Fisioterapia Aplicada à Neurologia, ${ }^{1,3}$ Residencia em Geriatria e Gerontologia, Campus de Presidente Prudente, SP.

${ }^{2}$ Universidade Estadual Paulista - UNESP, Curso de Fisioterapia, Campus de Assis, SP.

\section{RESUMO}

Introdução: Os músculos isquiotibiais estão expostos ao encurtamento devido à vida sedentária de algumas pessoas e ao longo período de tempo em que os indivíduos passam sentados. Objetivo: Verificar a incidência de encurtamento muscular de isquiotibiais em adultos jovens entre 18 e 25 anos de idade. Método: Estudo transversal, com 103 participantes que foram avaliados pela goniometria. Os pacientes foram posicionados em decúbito dorsal, membro inferior testado com quadril posicionado em $90^{\circ}$ de flexão, foi realizada extensão lenta e passiva do joelho pelo avaliador até o momento em que o indivíduo referiu desconforto nos isquiotibiais, para assim verificar o ângulo poplíteo. Resultados: Após avaliação 80,6\% dos participantes apresentaram encurtamento dos isquiotibiais, desses $79,5 \%$ mulheres e $20,5 \%$ homens. Conclusão: Conclui-se que grande percentual dos adultos jovens avaliados apresentaram encurtamento de isquiotibiais, e existe necessidade de orientação para esses indivíduos para proporcionar mais flexibilidade muscular e qualidade de vida.

Palavras Chaves: Encurtamento, isquiotibiais, Adultos jovens.

\section{ANALYSIS OF HAMSTRING MUSCLE SHORTENING IN YOUNG ADULTS FROM 18 TO 25 YEARS OLD}

\begin{abstract}
Introduction: The hamstring muscles are exposed to shortening because the sedentary lifestyle of some people the over time that individuals spend sitting. Objective: To determine the incidence of hamstring muscle shortening in young adults from 18 to 25 years old. Methods: Cross-sectional study with 103 participants who were evaluated by goniometry. The participants were positioned in supine, lower limb tested with hip positioned in $90^{\circ}$ of flexion, was performed slowly and passive knee extension by the evaluator until such time that the individual referred discomfort in the hamstring, so as to check the popliteal angle. Results: After evaluation $80.9 \%$ of the participants had showed shortened hamstrings, of those $79.5 \%$ women and $20.5 \%$ men. Conclusion: We conclude that a large percentage of young adults evaluated had shortened hamstrings, there is need for guidance for these young adults to provide more muscle flexibility and quality of life.
\end{abstract}

Key Words: Shortening, hamstrings, Young Adults. 


\section{INTRODUÇÃO}

Os isquiotibias são constituídos pela união dos músculos: bíceps femoral, semitendinoso e semimembranoso, que têm origem na tuberosidade isquiática e suas inserções na porção proximal da superfície medial do corpo da tíbia para semitendinoso, face póstero-medial do côndilo medial da tíbia para semimembranoso e côndilo lateral da tíbia para bíceps femoral; esses músculos atuam em conjunto com a função de extensão do quadril e flexão do joelho ${ }^{1,2,3}$.

Por serem extensores primários do quadril desempenham forte contração para estabilizarem a pelve durante a extensão do tronco e para controlarem a pelve sobre o fêmur à medida que o paciente em pé ou sentado, inclina-se para frente para tocar os pés e retornar a posição bípede $e^{2,3,4}$.

Os isquiotibiais em conjunto com a musculatura posterior do tronco constituem a cadeia muscular responsável pela manutenção e alinhamento postural, na qual é de extrema importância que a ação destes músculos esteja íntegra e sincronizada ${ }^{1,3}$.

A postura é definida como arranjo que os segmentos corporais mantêm entre si em determinada posição de maneira a proporcionar conforto, harmonia, economia e sustentação ao corpo $^{5}$. Assim, a postura prepara o indivíduo para realizar movimentos e que promovam sincronismo e sustentação ${ }^{1,7}$.

Desvios posturais podem mudar a estrutura de um músculo; alterar sua ação e modificar a descarga de peso, diminuir sua flexibilidade e mobilidade ou torná-lo encurtado e enfraquecido ${ }^{7}$. Fatores como idade, sexo, estrutura articular, ligamentos, tendões, músculos, pele, lesões, tecido adiposo, temperatura corporal e temperatura ambiente podem influenciar na flexibilidade e, consequentemente, a amplitude dos movimentos musculares e articulares ${ }^{7,8}$.

Os isquiotibiais são músculos biarticulares e estão sujeitos ao encurtamento principalmente devido às posturas e posições adotadas nos dias de hoje, nas rotinas diárias dos indivíduos adultos jovens que passam a maior parte do dia sentado e por um período de tempo prolongado $^{9,5}$.

Outro fator relevante é o sedentarismo, caracterizado pela falta ou grande diminuição de atividade física, leva o indivíduo à permanência por tempo prolongado na mesma posição, principalmente na posição sentado, deste modo a musculatura isquiotibial tende a se encurtar. Grande parte da população apresenta essas características, o que sugere uma alta incidência de encurtamento dos isquiotibiais ${ }^{9,6}$. Em posição sentada os tendões dos isquiotibiais estão frouxos e se encurtam para aumentar a tensão na musculatura, assim diminui a flexibilidade do músculo ${ }^{5,10}$.

A boa flexibilidade na musculatura isquiotibial parece estar associada a menor incidência de lesões lombares crônicas, as restrições impostas por estes encurtamentos podem resultar em lesões musculoesqueléticas e dificuldades nas atividades de vida diária ${ }^{10,11}$.

Déficits na flexibilidade desse grupo muscular podem provocar outras alterações, como contratura dos isquiotibiais mediais e laterais, o que resulta em posição de flexão de joelho, se a contratura for extrema resultará em limitação da amplitude de movimento de extensão do quadril e da inclinação anterior de tronco, também poderão ocorrer alterações posturais como retroversão pélvica, retificação da coluna lombar que alteram a marcha e provocam dores nos membros inferiores e até mesmo discrepância no comprimento destes ${ }^{1,2,7}$.

A contratura consiste na contração persistente dos músculos, encurtamento adaptativo da unidade musculotendínea e dos tecidos moles, o que leva a resistência significativa ao alongamento ativo e passivo, causando restrições na amplitude de movimento ${ }^{5}$. 0 controle neuromuscular ativo e a mobilidade passiva dos tecidos moles fazem com que o corpo realize movimentos livremente, sem limitações e sem controle durante atividades funcionais, importante para o corpo, uma vez que ele necessita do movimento ${ }^{6,8,13}$.

Todas essas alterações musculares causam comprometimento da biomecânica do movimento humano, o que afeta também a funcionalidade principalmente das articulações da 
coluna lombar, quadril e joelho ${ }^{3,14}$. O uso inadequado das capacidades estruturais e funcionais do corpo dão origens aos desvios posturais, assim podem gerar desconforto, incapacidade e dor, pois se relaciona com a gravidade e persistência das alterações posturais ${ }^{3,14}$.

Portanto o objetivo deste estudo foi verificar a incidência de encurtamento do grupo muscular isquiotibiais em adultos jovens de 18 a 25 anos.

\section{MÉTODO}

O presente estudo é uma pesquisa de caráter transversal que foi realizada em Assis/SP na Universidade Paulista, com objetivo de avaliar o índice de encurtamento muscular dos isquiotibiais em adultos jovens de 18 a 25 anos.

Este estudo foi aprovado pelo CEP - Comitê de Ética em Pesquisa, protocolo no 047649/2015. A avaliação ocorreu na Universidade Paulista, Câmpus de Assis/SP.

Participaram deste estudo, jovens entre 18 e 25 anos de idade, que não apresentaram disfunções musculoesqueléticas ou disfunções neurológicas congênitas ou adquiridas e que assinaram o Termo de Consentimento Livre e Esclarecido (TCLE). Não foram incluídos aqueles que não assinaram o TCLE, que não apresentaram idade entre 18 e 25 anos e os que não tiverem horários disponíveis para a avaliação.

Antes de o procedimento ser realizado, os voluntários receberam explicações a cerca do procedimento. A avaliação foi realizada em uma sala segura, sem expor o colaborador a qualquer tipo de risco e sem perturbações externas.

Os participantes responderam um questionário com dados pessoais, dados sobre atividade física (contidos no resultado) e em seguida foram submetidos à goniometria; para a medida da angulação poplítea foi usado goniômetro $\left(\mathrm{CARCl}-0,20 \times 0,05[\mathrm{CxL}]^{\circledR}\right)$.

Os participantes voluntários do teste foram posicionados em decúbito dorsal sobre a maca, o membro contralateral que não estava sendo testado permaneceu com extensão completa sobre a mesa de exame, dessa forma manteve-se o quadril em posição neutra para evitar compensações, tanto o joelho quanto o quadril foram estabilizados por faixa elástica rígida, sendo esta transpassada em cima da patela e espinha ilíaca ântero-superior, respectivamente ${ }^{15}$.

No membro inferior testado, o quadril foi posicionado em $90^{\circ}$, a articulação tibiotársica ficou livre, o braço fixo do goniômetro foi posicionado em direção ao trocânter maior do fêmur, com o eixo sobre o epicôndilo lateral femoral, posteriormente o avaliador realizou extensão lenta e passiva do joelho, até o ponto em que o indivíduo relatou sensação de desconforto dos músculos isquiotibiais, assim o braço móvel foi posicionado em direção ao maléolo lateral e obteve-se o ângulo que o participante atingiu, visto que $180^{\circ}$ é considerado o parâmetro de normalidade. $O$ teste foi realizado em ambos os membros inferiores, por um único avaliador, que estava apto para o procedimento, assim reduzindo viés dos resultados ${ }^{10,15,16,17,18,19}$.

Após o teste e análise do resultado, que ocorreram simultaneamente e executado pelo avaliador, o participante com encurtamento recebeu um folheto explicativo com a importância do alongamento; em quais momentos e tempos adequados para realizar e com ilustrações mais adequadas para seu encurtamento assim como verificado na avaliação.

Os resultados foram apresentados de forma descritiva, contendo média e desvio padrão para dados nominais e em percentuais para os dados numéricos.

\section{RESULTADOS}

A presente pesquisa teve participação de 103 pessoas, entre essas 83 mulheres e 20 homens com média de idade geral de 20,5 $\pm 2,45$ anos. Dentre os participantes, $80,6 \%$ apresentaram encurtamento dos isquiotibiais, desses 79,5\% eram mulheres e $20,5 \%$ eram homens. O sexo feminino apresentou média de Índice de Massa Corporal de $22,53 \mathrm{~kg} / \mathrm{m}^{2}$ e o sexo masculino $25,43 \mathrm{~kg} / \mathrm{m}^{2}$. 
Homens e mulheres foram divididos em Praticantes de Atividade Física (PAF) e Sedentários (S). Nesta divisão foram indagados se os mesmos sentiram dores durante a realização do teste, na qual esta informação e a discriminação dos dados referentes aos homens e mulheres encurtados, apresentam-se na Tabela 1. A frequência média de atividade física foi de 3 vezes na semana para homens e 4 vezes na semana para mulheres.

Tabela 01. Encurtamento muscular em homens e mulheres e relato de dores durante o teste em PAF e $S(n=103)$

\begin{tabular}{cccccc}
\hline Participantes & Apresenta & Não Apresenta \\
encurtamento & Dor no Teste & $\begin{array}{c}\text { Sem Dor no } \\
\text { Teste }\end{array}$ \\
\hline Homens & PAF & $75 \%$ & $25 \%$ & $0 \%$ & $100 \%$ \\
& S & $91,7 \%$ & 8,3 & $25 \%$ & $75 \%$ \\
\hline Mulheres & PAF & $50 \%$ & $50 \%$ & $7,1 \%$ & $92,9 \%$ \\
& S & $82,6 \%$ & $17,4 \%$ & $17,4 \%$ & $82,6 \%$ \\
\hline
\end{tabular}

Entre as mulheres PAF, 50\% eram flexíveis, ou seja, a cada 2 mulheres, 1 era flexível. Dentre as sedentárias, $14,5 \%$ não apresentavam encurtamento, ou seja, a cada 6,9 mulheres, 1 era flexível.

Dentre os homens PAF, 25\% eram flexíveis, então a cada 4 homens 1 era flexível, os sedentários 8,33\% não apresentaram encurtamento, ou seja, a cada 12 homens 1 era flexível.

Quanto a flexibilidade, a cada 6,67 (15\%) homens 1 não apresentou encurtamento e, a cada 4,88 (20\%) mulheres 1 não apresentou encurtamento.

\section{DISCUSSÃO}

Das 103 pessoas avaliadas no presente estudo, 83 pessoas apresentaram encurtamento dos isquiotibiais, 66 mulheres e 17 homens. Este resultado constitui um alto índice de encurtamento muscular, que também foi constatado em um estudo realizado em 2009, que avaliou diminuição de flexibilidade nos isquiotibiais em adultos jovens ${ }^{20}$.

No presente estudo, obteve-se maior participação de mulheres do que homens, onde a cada 6,67 homens, 1 não apresentou encurtamento, e a cada 4,88 mulheres, 1 não apresentou o problema, o que indica que as mulheres são mais flexíveis do que os homens. Esse dado já foi comprovado em outro estudo, onde encontraram em suas avaliações maiores amplitudes de movimento em extensão de joelhos nas mulheres, o que indica menor índice de encurtamento da musculatura isquiotibial no gênero feminino do que no masculino ${ }^{21}$.

A diminuição ou falta de atividade física associada ou não por longos períodos na postura sentada, é um dos fatores que levam ao encurtamento dos isquiotibiais ${ }^{14}$, que pode gerar diminuição da amplitude de movimento, dor, parestesia e desenvolver contraturas ${ }^{13,8}$. Estudo realizado com idosos praticantes de atividade física demonstrou níveis de bom a excelente de flexibilidade ${ }^{22}$ e notou-se aumento da flexibilidade em adultos que receberam um protocolo de exercícios para melhorar flexibilidade global e este também resultou em facilitação das ações cotidianas $^{23}$.

O presente estudo mostra a necessidade desses adultos jovens, em saírem do sedentarismo, serem acompanhados por profissionais da saúde e praticarem atividade física, com ênfase no treinamento de flexibilidade e orientações ergonômicas. Essa necessidade foi destacada em um estudo, no qual indica que ao ingressar na faculdade, grande parte dos acadêmicos deixa de praticar exercício físico e passam longos períodos em uma postura sentada, o que gera o risco de encurtamento de isquiotibiais e de desenvolver posturas viciosas ${ }^{22}$. 
Estudos mostram que o aumento do peso corporal, geralmente está acompanhado pelo sedentarismo, que transforma em obstáculo para uma vida mais ativa; em tarefas como sentar e levantar do solo ou da cadeira, pessoas com excesso de peso tem menor mobilidade e flexibilidade da musculatura corporal, o que leva a consequências sérias para saúde s.23. $^{23}$.

Durante a aplicação do teste não houve intercorrência, os participantes aderiram completamente ao exame físico, o instrumento de avaliação foi de baixo custo e o modo de avaliação simplista, sendo fatores que mostram a viabilidade da metodologia aplicada e ressalta sua replicabilidade.

\section{CONCLUSÃO}

Diante do exposto, conclui-se que $80,6 \%$ dos participantes apresentaram encurtamento dos isquiotibiais, o que mostra alto índice do problema nos avaliados e indica a necessidade de orientação, conscientização e acompanhamento desses adultos jovens por profissionais da saúde.

Vale destacar a importância de programas de alongamento e atividades físicas no cotidiano, trabalho, faculdade, a fim de manter e melhorar a funcionalidade muscular, prevenir possíveis quadros álgicos e alterações posturais crônicas e assim proporcionar qualidade de vida.

\section{REFERÊNCIAS}

Tanaka C, Farah A. Anatomia Funcional das cadeias Musculares. 1o ed. São Paulo: Ícone, 1997.

Hamil J, Knutzen K. Bases Biomecânicas do Movimento. 1ำed. São Paulo: Manole, 1999.

Kendal FP, McCreary EK, Provance PG. Músculos, provas e funções. 4o ed. São Paulo: Manole, 1995.

Smith LK, Weiss EL, Lehmkuhl DL. Cinesiologia Clínica de Brunnstrom. 5o ed. São Paulo: Manole, 1997.

Salter BR. Distúrbios e lesões do Sistema Musculoesquelético. 3 ed. Rio de Janeiro: MEDSI Médica e Científica, 2001.

Petter G, Dalla DN, Santos TS, Braz MM, Lemos JC. Fatores Relacionados ao Encurtamento dos Isquiotibiais: Um Estudo Bibliográfico. Santa Maria. Trabalho de Iniciação Científica da Universidade Federal de Santa Maria, 2012.

Kisner C, Colby LA. Exercícios Terapêuticos Fundamentos e Técnicas. 3o ed. São Paulo, Manole, 1998.

Reis FP. A Importância da Manutenção de bons níveis de flexibilidade nos trabalhadores que executam suas atividades laborais sentados. Revista produção - Santa Catarina, 2003. DOI: 10.14488/1676-1901.

Watkins J. Estruturas e função do sistema musculoesquelético. 1ํ ed. Porto Alegre: Artmed, 2001.

Comunello FJ. Benefícios do método pilates e sua aplicação na reabilitação. Instituto Salus, maiojunho 2011.2 Disponível em: http://www.pilatesfisios.it/ricerche\%20pdf/BENEFICIOS\%20DO\%20METODO\%20PILATES.pdf. Acesso em: 15 de Outubro de 2015. 
Amaro JL, Haddad JM, Trindade JCS, Ribeiro RM. Reabilitação do Assoalho Pélvico - Nas Disfunções Urinárias e Anorretais. 1ำed. São Paulo: Segmento Farma, 2005.

Falcão FRC. Correlação dos desvios posturais com dores musculoesqueléticas. R Ci méd biol, Salvador, v. 6, n. 1, p. 54-62, jan/abr., 2007. Disponível em: www.portalseer.ufba.br/index.php/cmbio/article/view/4150/3031. Acesso em: 25 de fevereiro de 2015.

Marques AP. Manual da goniometria. 1o ed. São Paulo: Manole, 1997.

Boldrini MC, Tomé F, Moesch J, Mallmann SJ, Oliveira UL, Roberti FN, Carvalho RA, Bertolini FRG. Avaliação da confiabilidade intra e interavaliadores e intertécnicas para três instrumentos que mensuram a extensibilidade dos músculos isquiotibiais. Fit Perf J. 2009 set-out;8(5):342-8. DOI:10.3900/fpj.8.5.342.p. https://doi.org/10.3900/fpj.8.5.342.p.

Cintra VFMC, Nicolau AR, Júnior PRA, Uchôa MMS, Veiga AHP. Influência da laserterapia associada ao alongamento passivo sobre o músculo isquiotibial. Revista ConScientiae Saúde, 2012;11(3):498505. DOI:10.5585/ConsSaude.v11n3.2842. https://doi.org/10.5585/conssaude.v11n3.2842.

Neves SM, Marcolino MA, Prado PR, Pinfildi EC, Barbosa IR, Furumoto AM. Flexibilidade dos músculos isquiotibiais em dois diferentes programas de alongamento estático. Disponível em: http://200.196.224.129/comunicacao/publicacoes/ics/edicoes/2012/01_janmar/V30_n1_2011_p79-83.pdf. Acesso em: 13 de maio de 2015.

Oliveira SIE, Wahrendorff VF. Efeito da crochetagem nos músculos isquiotibiais e tríceps sural [tese]. Brasília. Centro Universitário de Brasília, 2009.

Resende TJ, Oliveira RK. Analise epidemiológica de encurtamento dos músculos isquiotibiais em estudantes do curso de fisioterapia da Unip/Campus - Assis [tese]. São Paulo. Universidade Paulista, 2009.

Affonso AAF, Navarro RD. Avaliação do ângulo poplíteo em joelhos de adolescentes assintomáticos. Revista Brasileira de Ortopedia, v. 37, n. 10, p. 461- 466, 2002.

Guardagnine P, Olivoto R. Comparativo de flexibilidade em idosos praticantes e não praticantes de atividades físicas. Revista Digital. Buenos Aires - $\mathrm{N}^{\circ} 69$ - Fev de 2004. Disponível em: http://www.efdeportes.com/efd69/flexib.htm. Acesso em: 23 de outubro de 2015.

Coelho WC, Araújo SGC. Relação entre o aumento da flexibilidade e facilitações na execução de ações cotidianas em adultos participantes de programa de exercício supervisionado. Revista Brasileira de Cineantropometria \& Desempenho Humano ISSN 1415-8426. Disponível em: http://www.clinimex.com.br/artigoscientificos/RBC\%26DH_00_qualidade\%20de\%20vida\%20e\%20 flexibilidade\%20em\%20adultos.pdf. Acesso em: 23 de outubro de 2015.

Azevedo DG, Silva MR. Prevalência de encurtamento dos músculos isquiotibiais em universitários. Revista Inspirar: Movimento \& Saúde, v. 2, n. 4, p. 95- 103, 2010.

Fachini ML, Guimarães ACA, Simas NPJ. Nível de flexibilidade em adultos obesos participantes de um programa de reabilitação cardiovascular. Revista Digital - Buenos Aires - N 100 - Set de 2006. 
Disponível em: http://www.efdeportes.com/efd100/obesos.htm. Acesso em: 30 de outubro de 2015.

Lira AV, Silva BE, Araújo SGC. As ações de sentar e levantar do solo são prejudicadas por excesso de peso. Rev Bras Med Esporte [online], 2000, vol.6, n.6, pp.241-248. DOI://dx.doi.org/10.1590/S1517-86922000000600004. 